
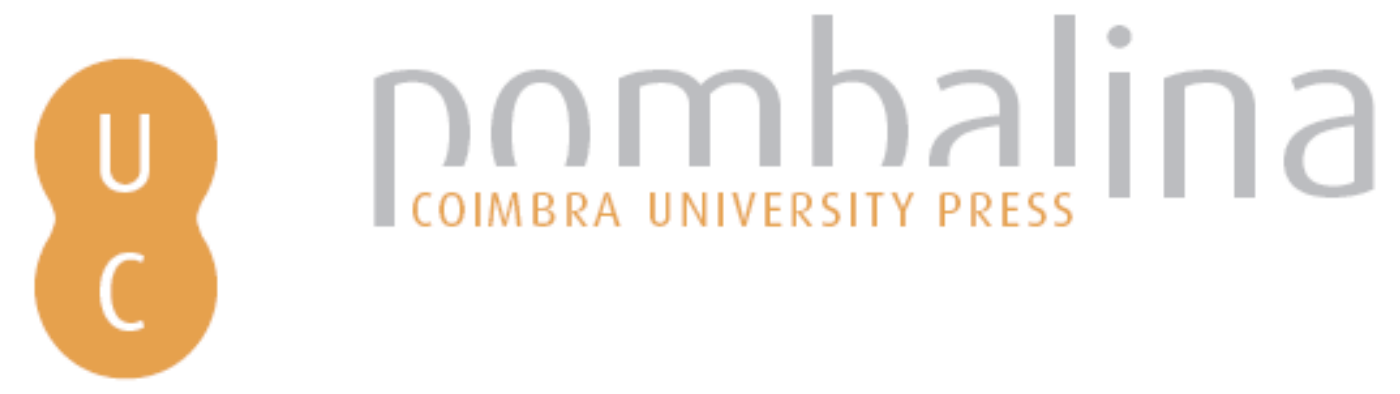

As produções naturais no Brasil: colónia e Brasil: reino: a química na interface com a história natural, a medicina e a mineralogia

Autor(es): $\quad$ Ferraz, Márcia H. M.

Publicado por: Imprensa da Universidade de Coimbra

URL

persistente: URI:http://hdl.handle.net/10316.2/31306

DOI: DOl:http://dx.doi.org/10.14195/978-989-26-0241-7_6

Accessed : $\quad$ 26-Apr-2023 08:43:26

A navegação consulta e descarregamento dos títulos inseridos nas Bibliotecas Digitais UC Digitalis, UC Pombalina e UC Impactum, pressupõem a aceitação plena e sem reservas dos Termos e Condições de Uso destas Bibliotecas Digitais, disponíveis em https://digitalis.uc.pt/pt-pt/termos.

Conforme exposto nos referidos Termos e Condições de Uso, o descarregamento de títulos de acesso restrito requer uma licença válida de autorização devendo o utilizador aceder ao(s) documento(s) a partir de um endereço de IP da instituição detentora da supramencionada licença.

Ao utilizador é apenas permitido o descarregamento para uso pessoal, pelo que o emprego do(s) título(s) descarregado(s) para outro fim, designadamente comercial, carece de autorização do respetivo autor ou editor da obra.

Na medida em que todas as obras da UC Digitalis se encontram protegidas pelo Código do Direito de Autor e Direitos Conexos e demais legislação aplicável, toda a cópia, parcial ou total, deste documento, nos casos em que é legalmente admitida, deverá conter ou fazer-se acompanhar por este aviso.

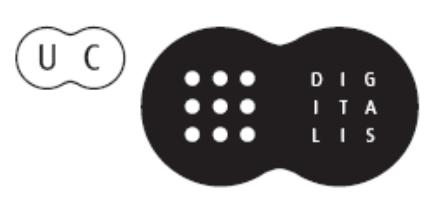




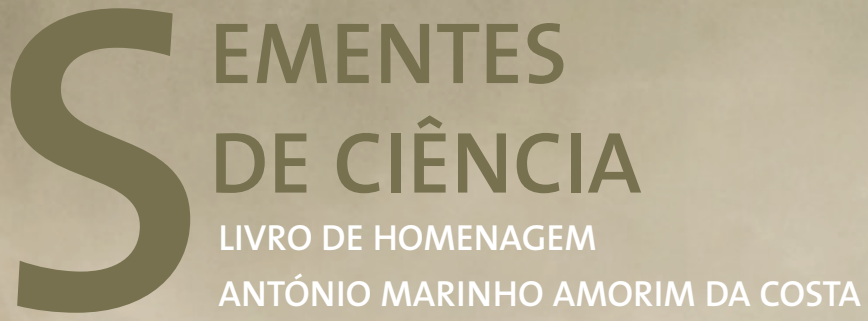

Sebastião J. Formosinho Hugh D. Burrows EDITORES 
Centro Simão Mathias e Programa de Estudos Pós-Graduados em História da Ciência, Faculdade de Ciências Exatas e Tecnologia, PUC-SP; Honorary Research Fellow, University College London

VI.

\section{AS PRODUÇÕES NATURAIS NO BRASIL - COLÔNIA E BRASIL - REINO: A QUÍMICA NA INTERFACE COM A HISTÓRIA NATURAL, A MEDICINA E A MINERALOGIA}

Entre 1992 e 1993 passei um ano entre Lisboa e Coimbra, enquanto realizava meu doutoramento. Tratava de complementar a pesquisa sobre as ciências em Portugal e no Brasil com ênfase no período entre 1772 e 1822, marcando 50 anos de grandes modificações no Reino português. A estada em Portugal foi bastante frutífera para a pesquisa e me deu também muitos bons amigos. De Coimbra, guardo com especial carinho a lembrança das conversas com o professor A. M. Amorim da Costa, conhecedor de boa parte dos documentos ligados ao tema da tese de doutorado defendida dois anos mais tarde. Muitos desdobramentos se concretizaram desde então, seja na forma de trabalhos individuais ou em grupo, seja na forma de dissertações e teses de orientandos. Pretendo aqui retomar alguns desses trabalhos, notadamente artigos e capítulos de livros, procurando compor um quadro, ainda que parcial, das ciências - com destaque para a química - em Portugal e no Brasil no período em questão. Assim, dedico, ao querido amigo, este trabalho que, de certa forma, contempla a trajetória da pesquisa desde a época das primeiras visitas a Coimbra, onde não me era permitido hospedar-me em outra parte que não fosse junto à sua família.

A pesquisa realizada até a elaboração da tese de doutorado, defendida em 1995 e transformada, posteriormente, em livro ${ }^{1}$, já havia apontado alguns aspectos dos estudos químicos das produções naturais presentes nos 
trabalhos de 'brasileiros'2 e portugueses sobre nossas terras. ${ }^{3}$ O interesse da pesquisa recaía, nessa época, nos trabalhos e estudos (mineralógicos e/ ou metalúrgicos) sobre os metais, a flora brasileira para uso medicinal, as águas minerais, os materiais que poderiam servir de corantes, a produção do salitre e sua utilização na fabricação da pólvora, ou, ainda, em menor escala, sobre a fabricação de sabões. ${ }^{4}$

Para tanto, foram abordados textos impressos ou manuscritos, tais como livros, memórias e periódicos; correspondências, documentos oficiais como as leis régias, as instruções, os decretos, etc.; além de ilustrações sobre as produções naturais do Brasil. Buscava-se identificar e formar um mapa das ideias em ciência no período estudado, com especial destaque para a química, procurando reconhecer ainda as interfaces desta com outras áreas do conhecimento. O estudo de textos sobre os mesmos assuntos elaborados em outras partes permitia verificar o compasso ou descompasso com relação ao realizado em Portugal e no Brasil.

As longas horas dedicadas a consultas de catálogos publicados de acervos e coleções, aliadas a visitas a arquivos e bibliotecas depositárias dos documentos sobre Portugal e Brasil no período, haviam mostrado a existência de uma imensa massa de materiais a ser explorada. Às bem conhecidas memórias dos naturalistas do século XviII e aos textos em química, história natural, medicina, mineralogia e metalurgia, entre outros, se somavam as publicações periódicas, como as Memórias publicadas pela Academia das Ciências de Lisboa, o Jornal de Coimbra e o "brasileiro" Patriota, formando um conjunto indicativo do muito a ser feito durante os anos seguintes.

Um importante desdobramento da pesquisa inicial concretizou-se na publicação de uma série de artigos e capítulos de livros tratando, mais especificamente e com certos detalhes, dos estudos sobre os medicamentos, as tintas e o salitre.

Tais estudos apontaram que a busca de materiais substitutos daqueles usados no 'velho' mundo foi intensa nos primeiros séculos depois da chegada dos europeus às terras americanas. Sem dúvida, os metais preciosos (notadamente o ouro e a prata) despertavam a mais intensa cobiça, mas, os alimentos tinham também sua importância, bastando lembrar, como exemplo, as inúmeras e já bem conhecidas descrições da mandioca e seu uso. Não 
menos importantes eram os materiais medicamentosos com eficácia fosse contra as doenças já conhecidas, fosse contra as recém 'descobertas'. Um problema geralmente enfrentado era o fato de as drogas - em sua maioria de origem vegetal - chegarem às colônias já deterioradas, sendo de pouca ajuda para os doentes. Por outro lado, as 'novas' doenças exigiam remédios também novos. Ao se tornar conhecido por suas virtudes medicamentosas, um novo remédio poderia ser incorporado nas indicações das farmacopeias. Assim, o item relativo aos medicamentos mereceu na literatura de viagem - tanto os relatos de viajantes quanto as memórias dos naturalistas - longas descrições.

De fato, a colônia portuguesa na América foi o tema de uma grande massa de textos encomendados aos 'viajantes naturalistas', principalmente a partir do último quartel do século XVIII, depois da reforma da Universidade de Coimbra, quando se estabeleceu o Curso Filosófico. Este curso tinha como um de seus objetivos preparar pessoas capazes para, a cargo do governo, realizar o reconhecimento das colônias, o que incluía descrever os materiais medicamentosos. Assim, vários desses 'naturalistas' compuseram trabalhos, publicados na forma de memórias e textos de matéria médica, sobre o Brasil, abordando um determinado medicamento, como a quina ou as drogas brasileiras, de forma geral, sem esquecer-se de mencionar a sua prescrição. Muitos desses autores trataram, ainda, de discutir como os medicamentos eram pensados em termos do quadro médico teórico na época. ${ }^{5}$

A quina, no início do século XIX, da mesma forma que em outros países, mereceu atenção especial dos estudiosos portugueses ligados a instituições como a Universidade de Coimbra e a Academia Real das Ciências de Lisboa, assim como o Laboratório Químico da Casa da Moeda, também em Lisboa. ${ }^{6}$ O problema principal enfrentado à época era verificar se os materiais desembarcados nos portos lusitanos como quina correspondiam de fato à verdadeira quina, Chinchona officinallis, conhecida por suas virtudes medicamentosas contra uma série de enfermidades. Muitas vezes, a única informação disponível sobre uma 'certa' quina era apenas o nome do porto de embarque na América, não sendo encontrados dados como a descrição botânica, a forma e menção às terras onde haviam sido coletadas. Assim, os médicos pediam ao 'químicos' para, através de análises, indicarem sua composição, o que algumas vezes, gerava controvérsias, como é o caso do 
debate entre Tomé Rodrigues Sobral e Bernardino António Gomes apresentado por A.M. Amorim da Costa. ${ }^{7}$ Gomes considerava a existência de um princípio responsável pelas propriedades medicinais das quinas e essa ideia foi também a base para um trabalho que publicou juntamente com José Bonifácio de Andrada e Silva e mais dois companheiros da Academia Real das Ciências de Lisboa. Tal texto aborda a 'quina do Rio de Janeiro', demonstrando a importância do tema tanto para a química quanto para a medicina da época. ${ }^{8}$

Entre os autores dedicados aos estudos de um conjunto de medicamentos e seu uso, podem ser destacados o mesmo Bernardino António Gomes (1768 1823) e José Maria Bomtempo (1774 - 1843), que fizeram publicar seus trabalhos no início do século XIX.? O primeiro ressalta a importância de se utilizar, no Brasil, remédios 'nativos', lembrando que uma medicina 'europeia' poderia não funcionar do outro lado do Atlântico. No intuito de colaborar na tarefa de tornar conhecidas as plantas medicinais brasileiras, Gomes compôs a memória "Observationes botanico-medicae de nonnullis brasiliae plantis", publicada pela Academia das Ciências de Lisboa em 1812.10 Seria de se esperar que tais ideias pudessem encontrar ecos nos trabalhos de pessoas ligadas às práticas médicas num período de dificuldades para fazer chegar ao Brasil os produtos europeus. Não é, entretanto o observado relativamente a outro estudioso do período. Veja-se o caso de Bomtempo, que tem seu Compendio de materia medica publicado em 1814, no Rio de Janeiro, na Impressão Régia. ${ }^{11}$ Como o primeiro professor da cadeira de matéria médica, criada no Brasil logo após a chegada da Corte em terras americanas, ele dedica o trabalho a seus alunos. A leitura desta obra mostra Bomtempo baseado nas ideias médicas de Erasmus Darwin para classificar as doenças e os remédios. Parece, entretanto, que o texto publicado no Brasil é um resumo da Zoonomie de Darwin, deixando pouco espaço para os medicamentos nativos. Apenas a copaíba recebeu de Bomtempo a observação de ser nativa do Brasil. Na verdade, a copaíba já fazia parte dos medicamentos americanos citados por E. Darwin e parece que Bomtempo tenta resumir ainda mais a lista presente no livro do estudioso britânico. Ele privou, assim, seus estudantes e futuros médicos de conhecerem através desse texto os remédios que poderiam ser facilmente encontrados no Brasil. ${ }^{12}$ 
Os estudos sobre os materiais corantes encontraram também grande espaço tanto na literatura dos 'naturalistas' e 'químicos' dos séculos XVIII e XIX, quanto entre as ordens reais portuguesas para busca e obtenção desses materiais nas colônias. No caso do Brasil, o empenho maior era para a produção do anil e da tinta vermelha da cochonilha.

$\mathrm{O}$ anil pode ser obtido de plantas como a Isatis tinctoria e a Indigofera tinctoria, sendo a primeira, de vegetação fácil em climas temperados, produzindo o pastel. Fonte de riqueza de algumas regiões europeias até o final do século xvi, o pastel foi chamado de 'ouro azul'. Ao final desse período, o pastel dá lugar ao azul obtido de diversas espécies de Indigofera, provenientes da Índia. Nas Américas, onde também se encontravam espécies dessa planta, a tinta era produzida pelos nativos em diferentes regiões. Diferente de outras partes onde os colonizadores procuraram aprender a técnica de produção da tinta azul, no Brasil a presença da planta, nativa na costa brasileira, parece não ter despertado, até finais do século XVII, a atenção dos portugueses. ${ }^{13}$ Nessa época, o governo da Bahia solicitou que fossem enviadas, da Índia, sementes de planta. Apenas um século depois, se verifica a preocupação em publicar textos destacando a preparação do índigo, como é o caso da coletânea O fazendeiro do Brasil, com volumes dedicados especialmente à tinturaria. ${ }^{14}$ Ainda que memórias, como as de Alexandre Rodrigues Ferreira tenham se ocupado em discutir o assunto, esses trabalhos, entretanto, permaneceram inéditos até bem avançado o século XIX, sem poder contribuir para a divulgação do conhecimento sobre as técnicas de plantio do vegetal e a produção do anil. ${ }^{15}$

Tal produção exigia passos razoavelmente bem conhecidos em sua forma geral: partes das plantas eram colhidas, geralmente quando se iniciava a floração, e colocadas em um tanque, com água, para que ocorresse a fermentação. Esse tanque se comunicava com um segundo, para onde apenas o líquido resultante da fermentação era transferido. Aí, o líquido era batido durante várias horas, até a separação de um sólido de cor azul que era recolhido e posto a secar. O material seco, na forma de pequenas 'pedras', era utilizado para tingir ou 'branquear' fios e tecidos de lã, algodão e seda.

No texto O Fazendeiro do Brasil, encontramos desde recomendações sobre a forma de se plantar as diferentes espécies e construir as fábricas, 
até algumas explicações químicas para o processo de produção do anil. Segundo o que se pensava no período, a fermentação começava a promover a reunião das partículas colorantes, resultando num líquido verde, pois partículas azuis e amarelas estariam ainda juntas. O processo de bater o líquido fermentado promovia a separação das partículas colorantes azuis que se juntavam e depositavam no fundo do segundo tanque. O auge da produção do anil no Brasil aconteceu em finais do século XVIII quando várias centenas de fábricas se encontravam em funcionamento, principalmente no Rio de Janeiro, mas, também na Bahia e no Pará. Em alguns períodos, chegou-se a exportar cerca de 100 toneladas do produto, o que supria as necessidades das fábricas portuguesas de tecidos e, ainda, sobrava para a reexportação. Nos primeiros anos do século XIX, o comércio do anil brasileiro passa a declinar, pois não consegue competir com a produção indiana, promovida pela Inglaterra, que chegava aos mercados por preços menores. Além disso, o produto brasileiro estava desacreditado devido às constantes reclamações de adulteração e má qualidade. ${ }^{16}$

Outro corante muito procurado no período em questão era a chamada cochonilha da América, pois dava aos tecidos uma maravilhosa cor vermelha resistente às lavagens e à luz solar, propriedades raramente encontradas em conjunto. ${ }^{17}$ Os europeus haviam conhecido no México, com os nativos, tanto os pequenos animais quanto a forma de utilizar um material que se mostrara um excelente substituto para antigos materiais conhecidos por sua propriedade de tingir fios e tecidos de vermelho. Um deles era o múrice (ou murex), molusco utilizado na Antigüidade (para a preparação da Púrpura de Tiro) que havia dado lugar ao quermes durante a Idade Média. A eles se pode acrescentar a Cochonilha da Polônia e a Cochonilha da Armênia, muito procuradas no Renascimento.

Os detalhes dos processos de preparação da tinta vermelha aprendidos com os nativos mexicanos eram guardados como segredos de estado pelo governo espanhol, pois sua produção e comercialização significavam grande entrada de divisas. Sabia-se, no entanto, ser a tinta produzida a partir da decocção da carapaça da fêmea de um inseto que se reproduzia nas palmas de cactos denominados nopales. A mais cobiçada pela qualidade da tinta, era a conhecida como mesteca ou cochonilha fina sendo cultivada principalmente 
em Oaxaca, Puebla, Tlaxcala e regiões vizinhanças. Já a outra, a cochonilha silvestre, podia ser encontrada em muitas outras regiões, inclusive no Brasil. Assim, poucos eram autorizados pelos espanhóis a chegar perto do local de cultivo da cochonilha fina. Mas, não faltaram tentativas para se descobrir tais segredos. É o caso da bem conhecida empreitada de N. J. Thiéry de Menonville (1739 - 1780) que teria se deslocado à América, chegando a São Domingos, então colônia francesa (atual Haiti), onde conseguiu um passaporte para Havana. Para disfarçar seus verdadeiros interesses, passava boa parte do dia em Havana coletando plantas e herborizando, além de atender, como médico, as pessoas do local. Passado algum tempo, ganhou a confiança dos governantes espanhóis e pôde partir para Vera Cruz e depois Oaxaca. Uma vez no centro de produção da cochonilha, Thiéry de Menonville procurou aprender todas as etapas do processo de obtenção do corante. Ao voltar a São Domingos, conseguiu levar grandes caixas com cactos e insetos, sob o pretexto de que seriam para a preparação de um ungüento para a gota.

Essas e outras façanhas, assim como os segredos para a preparação da cobiçada tinta vermelha, foram reveladas por Thiéry de Menonville num livro que acabou ganhando uma tradução ao português e foi publicada em um dos tomos do Fazendeiro do Brasil mencionado acima. A intenção era promover em terras brasileiras a plantação do cacto em extensas faixas de areia no Rio de Janeiro onde se poderia desenvolver a cochonilha. O argumento principal para a escolha desta região residia no fato de se encontrar o Rio de Janeiro ao sul na mesma latitude do México ao norte; assim, seria possível ter ao sul os mesmos bons resultados verificados no norte. Juntamente com o texto de Thiéry de Menonville e na mesma tipografia dirigida pelo Frei José Mariano da Conceição Veloso, saem outros dedicados à cochonilha numa ação orquestrada para desenvolver tais atividades no Brasil. Interessante notar que cerca da mesma época de publicação destes trabalhos, D. Rodrigo de Souza Coutinho envia Hipólito José da Costa, nascido no sul do Brasil, para uma viagem de dois anos à América do Norte com a incumbência de repetir, de certa forma, o que fizera Thiéry de Menonville. Os resultados não foram, entretanto, da mesma monta como se pode ler nas memórias de viagem do estudioso 'brasileiro'. ${ }^{18}$ 
Um aspecto relevante a se destacar no material estudado diz respeito às explicações químicas para alguns fenômenos. Um bom exemplo é a discussão de como se daria a formação do material vermelho responsável pela cor da tinta obtida da cochonilha, pois os pequenos insetos se alimentavam do 'suco' verde dos cactos e chegavam a vermelho quando estavam 'maduros'. A razão disso deveria estar na 'transmudação' do suco da planta que se combinava com certos princípios de animalização do inseto. Isto posto, esperava-se que a química pudesse 'imitar' a natureza e fazer o mesmo partindo também do suco da planta. A pesquisa mostrou ainda ter sido a cochonilha do Rio de Janeiro analisada mesmo fora do Reino português, quando se concluiu ser de boa qualidade. Porém, mais uma vez, apesar do empenho do governo português na publicação de textos enviados ao Brasil e do incentivo à 'semeadura' da cochonilha, este gênero não produziu tantas divisas quanto se esperava.

O salitre é outro material que tem lugar em muitas das 'orientações' emitidas pelo governo português a seus representantes no Brasil. Esse gênero era tão importante para a fabricação de materiais explosivos - como a pólvora - que foi objeto de inúmeros trabalhos e teve a atenção de estudiosos como Lavoisier, por exemplo. De fato, o 'químico' francês encontrava-se, em finais do século XVIII, à frente da Administração da Pólvora e do Salitre preocupado com os aspectos da produção e das explicações químicas dos processos envolvendo esses materiais.

Em Portugal não foi diferente, pois o corpo universitário de Coimbra esteve empenhado em fabricar, no Laboratório Químico da instituição, com muito pouco salitre disponível, a pólvora necessária para a defesa da cidade quando da invasão dos franceses em 1808.

De toda forma, a produção do salitre ocupava uma boa parte das preocupações dos governos - e dos 'químicos' - em finais do século XVIII e início do século xix. Nessa época, se considerava que os compostos nitrogênio proviriam de três fontes: 1) as salitreiras naturais; 2) as salitreiras artificiais e, 3) o ar. ${ }^{19}$

As salitreiras naturais eram objetos notadamente dos viajantes naturalistas, pois fazia parte de suas obrigações relacionar os locais de onde se poderia extrair o material, além de indicar os meios como se daria o processo. 
Em alguns casos, estes naturalistas, utilizando os meios rudimentares à disposição, procuraram avaliar, através das análises químicas, a porcentagem do salitre nas nitreiras naturais.

Já as nitreiras artificiais foram objeto do trabalho de diversos estudiosos do período. Para apresentar brevemente este assunto, nada melhor do que abordar os trabalhos de José Vieira Couto. Ele escreveu a "Memória sobre as salitreiras de Monte Rorigo: maneira de as auxiliar por meio das artificiais; refinaria do nitrato de potassa, ou salitre”, publicada apenas em 1840 cerca de quatro décadas depois de sua elaboração - em O Auxiliador da Indústria Nacional. Segundo Couto, existiria uma grande semelhança entre as condições das salitreiras artificiais e aquelas naturais, nas cavernas. Ele descreve em detalhes como se deveria construir uma salitreira artificial para, em seguida, passar às explicações químicas dos processos envolvidos. Uma questão importante para todos os interessados em produzir salitre artificialmente estava em escolher e preparar as terras denominadas 'pais do azoto'. A sugestão de Couto, seguindo de perto uma tradição que já remontava vários séculos, era de se utilizar restos de vegetais e de animais, lixo e estrumes diversos, terras de cemitérios e adegas, lama de latrinas e charcos. Todos esses materiais, conforme nos diz Couto, eram tidos como abundantes em 'princípios salitrificáveis'. Para tornar os resultados mais efetivos, nosso autor recomenda - seguindo, uma vez mais, uma antiga receita - 'regas' das salitreiras com águas de estrumes ou ainda aquelas provenientes de esgotos e latrinas misturadas com sangue de animais, urinas, etc.

O ar seria mais uma das fontes de materiais para a preparação de compostos nitrogenados. Ainda que isso só viesse a se concretizar no início do século $\mathrm{xx}$, tal proposta estava solidamente alicerçada nas ideias de A.-L. Lavoisier e seus trabalhos de análise e síntese, presentes na 'Nova Química'. Nessa linha, encontramos a memória de Luiz da Sequeira Oliva apresentada à Academia Real das Ciências de Lisboa, provavelmente em finais do século XVIII. O trabalho (nunca publicado) intitulado: "Algumas observações sobre a existência do salitre entre nós" ${ }^{20}$, enfatiza a abordagem teórica e procura demonstrar a possibilidade teórica de tal síntese. ${ }^{21}$

Os exemplos apresentados mostram diversos aspectos dos trabalhos e estudos sobre as tintas, os medicamentos e o salitre realizados em Portugal 
e no Brasil entre finais do século XVIII e início do século XIX. Procurou-se verificar as ideias em ciência presentes nos textos sobre as produções naturais do Brasil, com especial destaque para a química, sem negligenciar, entretanto, as interfaces dessa com outras áreas do conhecimento, como são a história natural, a medicina e a mineralogia, por exemplo. Foi possível perceber grande empenho dos governos no sentido de tornar possível a exploração de materiais que traziam riqueza a outros países ou eram necessários a Portugal. Nesse sentido, foram elaborados ou traduzidos e publicados muitos textos para auxiliar a quem se decidisse por desenvolver tais atividades. Nota-se também o conhecimento, por parte de seus autores, das ideias em ciência veiculadas nos melhores centros europeus. Os resultados, entretanto, não chegaram a satisfazer os envolvidos nas diversas instâncias. No caso do Brasil, especificamente, faltava uma tradição de trabalhos e estudos em ciência que pudesse alicerçar a implantação e desenvolvimento de novas ideias. E, não poderia ser diferente, pois até a chegada da Família Real Portuguesa ao Brasil estava aí proibida a instalação tanto de cursos superiores como da imprensa, sendo o comércio de livros estritamente controlado. A quem resolvesse se dedicar ao estudo das ciências só restava partir para a Metrópole, após ter conseguido uma autorização específica. Assim, as medidas governamentais, por mais bem pensadas e incisivas que fossem, acabavam por não encontrar ecos em terras brasileiras.

\section{Referências}

${ }^{1}$ As ciências em Portugal e no Brasil (1772-1822): o texto conflituoso da química, São Paulo, EDUC/FAPESP, 1997.

${ }^{2}$ Utilizaremos, em nosso trabalho, o termo "brasileiro", para designar as pessoas nascidas no Brasil.

${ }^{3}$ A pesquisa sobre temas relacionados ao Brasil teve seu início bem antes dos trabalhos de doutorado. De fato, 1988 marca o primeiro artigo elaborado em conjunto com A. M. Alfonso-Goldfarb - orientadora dos trabalhos de pós-graduação -, intitulado "Reflexões sobre uma história adiada: trabalhos e estudos químicos e pré-químicos brasileiros”, Quipu, 5 (setembro-dezembro, 1988): 339-53. A esse, seguem-se muitos outros sobre diversos aspectos dos estudos e trabalhos em ciência no Brasil.

${ }^{4}$ Nos vários capítulos do livro, op. cit., são abordados esses aspectos procurando reconhecer o conhecimento químico presente nas discussões.

${ }^{5}$ M. H. M. Ferraz \& A.M. Alfonso-Goldfarb, "A química médica no Brasil colonial: o papel das novas terras na modificação da farmacopéia clássica”, in: A.M. Alfonso-Goldfarb e C.A. Maia, org., 
História da ciência: o mapa do conbecimento, Rio de Janeiro/Expressão e Cultura; São Paulo/EDUSP, 1995; pp. 693-709

${ }^{6}$ Ver: M.H.M. Ferraz, en la literatura química-médica portuguesa de los inicios del siglo XIX", in Aceves Pastrana, org., Farmacia, História Natural y Química Intercontinentales, Coleção: Estudios de historia social de las ciencias químicas y biológicas; volume 3, México, DF, Univ. Autónoma Metropolitana, 1996, pp. 189-202.

${ }^{7}$ Ver esse debate em seu livro: Primórdios da ciência Química em Portugal, Lisboa, 1984, p. 91 et seq.

${ }^{8}$ Ver "Los estudios sobre las quinas...", op. cit.

${ }^{9}$ Essa discussão está presente no artigo: A.M. Alfonso-Goldfarb e M.H.M. Ferraz, "Las miradas extranjeras/autóctonas sobre la terra brasilis independiente: ciencia y salud entre el Imperio y la República”, in F. J. Puerto Sarmiento, et. alii, 1898. Sanidad y Ciencia en España y Latinoamérica durante el cambio de siglo; Madrid, Univ. Complutense de Madrid / Doces Calles, 1999, pp. 43-50.

${ }^{10}$ Ver as Memórias da Academia Real das Sciencias de Lisboa, tomo III, vol. 1, 1812, pp. 1-104.

${ }^{11}$ José Maria Bomtempo, Compêndios de Matéria médica, Rio de Janeiro, Regia Of. Typografica, 1814 .

${ }^{12}$ A discussão está contemplada em: M.H.M. Ferraz, "Matière Médicale luso-bresilienne au début du XIXe. siècle" e "Medicina en Brasil-Reino: el trabajo de José Maria Bomtempo" e Idem, "Medicina en Brasil-Reino: el trabajo de José Maria Bomtempo", in P. Aceves Pastrana, org., Tradiciones e intercambiod científicos: materia médica, farmacia y medicina", Coleção: Estudios de historia social de las ciencias químicas y biológicas; volume 5, México, DF, Univ. Autónoma Metropolitana, 2000, pp. 217-227.

${ }^{13}$ M.H.M. Ferraz, "Saberes antigos e ciência moderna: a produção do anil no Brasil Colonial", ". Anais do VII Seminário Nacional de História da Ciência e da Tecnologia e VII Reunião da Rede de Intercâmbios pra a História e a Epistemologia das Ciências Químicas e Biológicas. São Paulo, Edusp/ Sociedade Brasileria de História da Ciência, 2000, pp. 175-180

${ }^{14}$ O Fazendeiro do Brasil, melhorado na Economia Rural dos Generos já cultivados, e de outros que se tem escrito a este assunto, coligido de memorias estrangeiras, Lisboa, Tip. Calcographica do Arco do Cego e Régia Of. Tipographica, 1798-1806, 10 volumes.

${ }^{15}$ Ferreira, "Diário da viagem philosophica pela Capitania de São-José do Rio-Negro", Revista Trimensal do Inst. Hist., Geog. e Etnográfico do Brasil (RIHGB), 48(1885), pp. 115 et seq.

${ }^{\circ}$ Fazendeiro do Brasil, op.cit., tomo II, parte 1.

${ }^{16}$ Ver o artigo: "Saberes antigos e ciência moderna: a produção do anil no Brasil Colonial", op. cit.

${ }^{17}$ O que se segue está baseado no artigo: M.H.M. Ferraz, "A rota dos estudos sobre a cochonilha em Portugal e no Brasil no século XIX: caminhos desencontrados”, Quim. Nova, Vol. 30, No. 4, 1032-1037, 2007.

${ }^{18}$ Ver: "A rota dos estudos sobre a cochonilha...", op. cit.

19 M.H.M. Ferraz, "A produção do salitre no Brasil Colonial", Química Nova, 23(6), pp. 845-850, novembro-dezembro 2000. Os estudos sobre os materiais nitrogenados em diferentes períodos foram temas de dois projetos coordenados por A. M. Alfonso-Goldfarb e financiados pelo CNPq, a agência federal brasileira de fomento à pesquisa. No âmbito desses projetos foram realizados encontros e publicações. No caso específico desta pesquisadora, a escolha recaiu sempre nos assuntos relativos a Portugal e Brasil: "A fabricação do salitre no Brasil Colonial: Estabelecimento de um corpo documental em arquivos e bibliotecas", in: XV Reunión Internacional da RIHECQB y Reunión internacional instituciones y personalidades trayectoria vital, Buenos Aires : FEPAI, 2005. v. 1; "Trabalhos e estudos sobre as 'nitreiras artificiais': Portugal e Brasil no período colonial", in A.M. Alfonso-Goldfarb, M.H.M. Ferraz e L. Zaterka (Org.), Atas do CESIMA Ano X, São Paulo: CESIMA-PUCSP, Fapesp, Ed. Liv. Fisica, Thomson Gale, 2006.

${ }^{20}$ Manuscrito da Academia das Ciências de Lisboa, Ms Azul, 374, tomo 2, manuscrito 26.

${ }^{21}$ Ver: "A produção do salitre no Brasil Colonial", op. cit. 